\title{
Marginal and Internal Precision of Zirconia Four-Unit Fixed Partial Denture Frameworks Produced Using Four Milling Systems
}

\author{
Karl Martin Lehmann ${ }^{1, *}$, Michael Weyhrauch ${ }^{1}$, Monika Bjelopavlovic ${ }^{1}$, Herbert Scheller ${ }^{1}$, Henning Staedt ${ }^{2}$, \\ Peter Ottl ${ }^{2,3}$, Peer W. Kaemmerer ${ }^{4}$ (i) and Stefan Wentaschek ${ }^{1}$ \\ 1 Department of Prosthodontics and Materials Science, University Medical Center of University of Mainz, \\ Augustusplatz 2, 55131 Mainz, Germany; michiweyhrauch@googlemail.com (M.W.); \\ monika.bjelopavlovic@unimedizin-mainz.de (M.B.); scheller@mail.uni-mainz.de (H.S.); \\ stefan.wentaschek@unimedizin-mainz.de (S.W.) \\ 2 Department of Prosthodontics and Materials Science, University of Rostock, Strempelstr. 13, \\ 18057 Rostock, Germany; henning@staedt.com (H.S.); peter.ottl@med.uni-rostock.de (P.O.) \\ 3 Department Life, Light \& Matter, University of Rostock, Albert-Einstein-Straße 25, 18059 Rostock, Germany \\ 4 Department of Oral- and Maxillofacial Surgery, University Medical Center of University of Mainz, \\ Augustusplatz 2, 55131 Mainz, Germany; peer.kaemmerer@unimedizin-mainz.de \\ * Correspondence: drkarllehmann@gmail.com; Tel.: +49-6131-172211
}

\section{check for}

updates

Citation: Lehmann, K.M.; Weyhrauch, M.; Bjelopavlovic, M.; Scheller, H.; Staedt, H.; Ottl, P.; Kaemmerer, P.W.; Wentaschek, S. Marginal and Internal Precision of Zirconia Four-Unit Fixed Partial Denture Frameworks Produced Using Four Milling Systems. Materials 2021, 14, 2663. https://doi.org/ $10.3390 /$ ma14102663

Academic Editor: Bruno Chrcanovic

Received: 11 April 2021

Accepted: 13 May 2021

Published: 19 May 2021

Publisher's Note: MDPI stays neutral with regard to jurisdictional claims in published maps and institutional affiliations.

Copyright: (c) 2021 by the authors. Licensee MDPI, Basel, Switzerland. This article is an open access article distributed under the terms and conditions of the Creative Commons Attribution (CC BY) license (https:// creativecommons.org/licenses/by/ $4.0 /)$.
Abstract: Background: CAD/CAM systems enable the production of fixed partial dentures with small and reproducible internal and marginal gaps. Purpose: The purpose of this study was to evaluate the reproducibility of the marginal and internal adaptations of four-unit fixed partial denture frameworks produced using four CAD/CAM systems. Materials and Methods: Prepared dies of a master model that simulated the loss of the first left molar were measured. Fifteen frameworks were manufactured using four CAD/CAM systems (A-D). The internal fit was determined by the replica technique, and the marginal gap was determined by microscopy. ANOVA was carried out to detect significant differences, and the Bonferroni adjustment was performed. The global level of significance was set at 5\%. Results: The mean gap size ranged from 84 to $132 \mu \mathrm{m}$ (SD $43-71 \mu \mathrm{m})$. The CAD/CAM systems showed significant variance $(p<0.001)$, and system A (VHF) showed the smallest gaps. The smallest gaps for each system were in the molar part and in the marginal region of the frameworks $(p<0.001)$. Conclusions: The CAD/CAM systems showed significantly different gap sizes, particularly between premolars and molars and among the marginal, axial and occlusal regions. All of the systems are suitable for clinical application.

Keywords: marginal fit; internal fit; zirconia; FPD; CAD/CAM

\section{Introduction}

All-ceramic materials are used widely in dentistry and have excellent biocompatibility and esthetics [1-3]. The demand for convenient, metal-free dentures has increased significantly in recent years. In particular, the excellent translucency of zirconia (ZrO2) in combination with an all-ceramic veneering material makes it suitable for fixed partial dentures (FPDs) [3-5]. Zirconia has a flexural strength from 900 to $1200 \mathrm{MPa}$ and resists dispersion of cracks by undergoing a crystalline phase transformation [6-8]. Zirconia can be stabilized by yttrium oxide by sintering for up to $7.5 \mathrm{~h}$ at $1500{ }^{\circ} \mathrm{C}$. With sintering, the dimensions of the restoration shrink from approximately $15 \%$ to $25 \%$ [8]. Due to its high stability, zirconia dental restorations can be cemented conventionally, unlike other all-ceramic materials.

With the development of computer-aided design (CAD)/manufacturing (CAM) technologies, which enable milling of pre-sintered zirconia, all-ceramic materials have become established in dentistry [8]. Compared to conventional techniques for producing all-ceramic 
dentures, $\mathrm{CAD} / \mathrm{CAM}$ technologies have a simpler manufacturing process, because the design, for example, the construction of the connectors, can be made virtually predictable $[7,8]$. Furthermore, all-ceramic materials offer the potential for better aesthetics [1,4]. The fabrication of frameworks or copings range from single-tooth restorations to 14-unit bridges (Figure 1) [9]. Furthermore, in the meantime, CAD/CAM-based removable dentures have been produced [10].

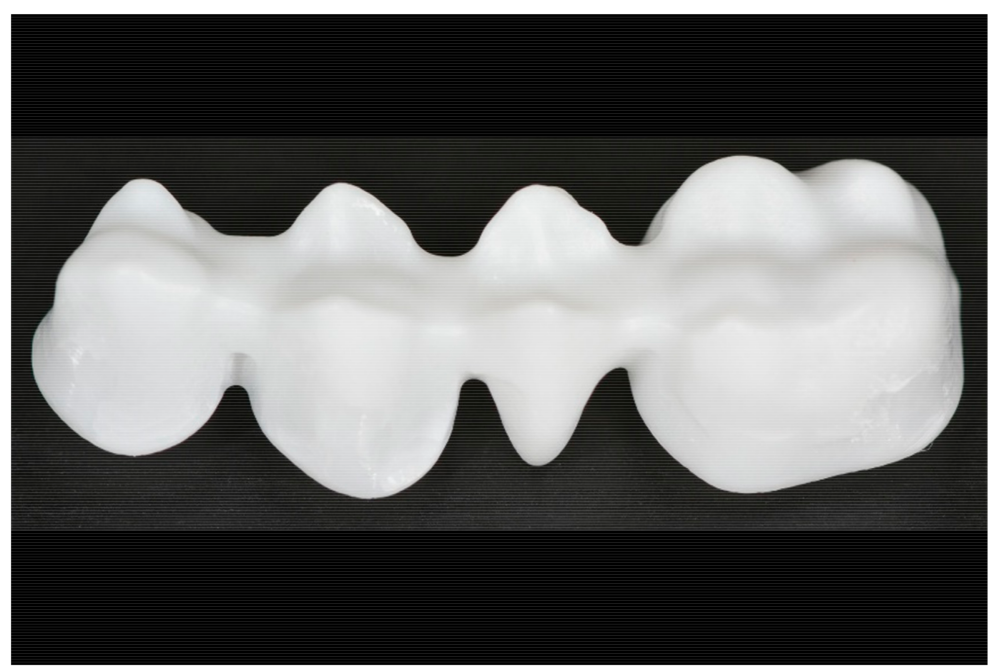

Figure 1. Zirconia four-unit framework.

The preparation is usually scanned. Therefore, different scanning systems are available, for example, Primescan (Sirona, Bensheim, Germany), CS3600 (Carestream, Rochester, Germany) or Trios 4 (3Shape, Kopenhagen, Denmark) for intraoral scanning and inEOS X5 (Sirona, Bensheim, Germany) or 3Shape (3Shape, Kopenhagen, Denmark) scanner for laboratory scanning procedures [11]. These scanning devices can also be used for removeable dental and craniofacial prothesis production $[12,13]$ and based on the data, fixed partial dentures (FPDs) are designed using different software tools. After milling, the dentures must be sintered and fitted to the die $[8,9,14,15]$.

The marginal and internal fit are important factors for the long-term wear of FPDs. Secondary caries and decementation or gingival irritation can result from an insufficient crown margin [16-25]. Furthermore, poorly fitted restorations render a tooth susceptible to pulpitis. If the internal fit is inadequate, strength and retention are reduced. The clinically acceptable marginal gap is reportedly 50 to $100 \mu \mathrm{m}$ [15-17] or $<120 \mu \mathrm{m}[26,27]$. Regarding this, there are basically different types of preparation, for example, knife edge finish line, bevel, chamfer, shoulder, shoulder bevel or modified shoulder/heavy chamfer preparation, whereas Beuer et al. reported the accuracy of fit as a function of preparation angle $\left(4^{\circ}, 8^{\circ}\right.$ and $12^{\circ}$ ) with the smallest gap for a $12^{\circ}$ preparation angle [14]. However, as is well known, a larger angle goes hand in hand with less friction and a medium preparation angle is a good compromise. Therefore, it is important to use manufacturing systems that achieve small gaps of reproducible sizes.

In this study, we evaluated the marginal and internal fits of zirconia four-unit FPD frameworks produced using four milling systems, similar to the study by Vigolo and Fonzi [28].

The null hypothesis of this study is that there would be no difference in gap sizes among the CAD/CAM systems tested and no difference between molars and premolars or among the marginal, axial and occlusal regions using each system. 


\section{Materials and Methods}

\subsection{Master Model Preparation}

A master model was manufactured (base metal alloy) to simulate loss of the first left mandibular molar, a frequent clinical situation. The premolars and the second molar were both prepared with a taper of $8^{\circ}$ in a chamfer design to ensure an ideal combination of sufficient margin thickness and good visibility of the preparation margin to contain a bridge framework. The model was powdered (Dentaco Dentalindustrie und Marketing $\mathrm{GmbH}$, Bad Homburg, Germany) and scanned using a Cerec system (Sirona Dental Systems GmbH, Bensheim, Germany).

\section{2. $C A D / C A M$ Design}

FPDs were designed using Cerec three-dimensional (3D) software (Sirona, Bensheim, Germany) and Exocad (DentalCAD, Exocad GmbH, Darmstadt, Germany). A four-unit bridge framework was designed to replace the first lower molar (Figure 1). The default settings were a $10 \mu \mathrm{m}$ cement spacer starting from $1 \mathrm{~mm}$, a milling correction of $1.4 \mathrm{~mm}$ and an additional distance of occlusal from $0 \mathrm{x} / \mathrm{y}$ to $0.01 \mathrm{~mm}$. Next, 15 duplicates of each pre-sintered and yttria-stabilized zirconia framework (Metoxit AG, Thayngen, Switzerland) were manufactured from the extended STL data set with the following milling systems: VHF CAM 4-02 Impression (dry milling) (exocad, System A, VHF Camfacture AG, Ammerbuch, Germany), Datron D5 (dry milling) (exocad, System B, Datron AG, Traisa, Germany), Cerec MCXL (wet milling) (Cerec inEos, System C, Sirona, Bensheim, Germany) and Roland DWX-50 (dry milling) (exocad, System D, Roland DG Deutschland GmbH Center, Willich, Germany) (Figure 2).

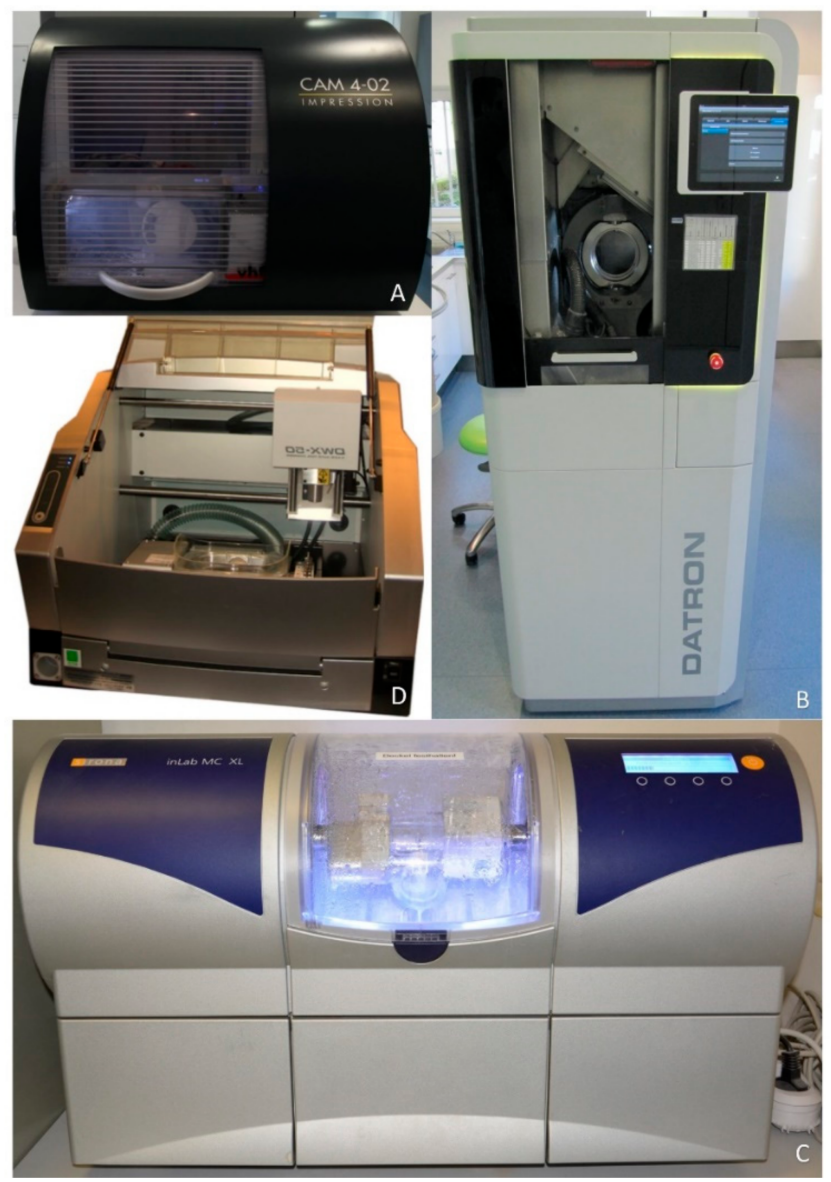

Figure 2. CAM Systems. System (A) (VHF CAM 4-02 Impression), system (B) (Datron D5), system (C) (Cerec MCXL) and system (D) (Roland DWX-50). 
After milling, the frameworks were sintered at a maximum of $1450{ }^{\circ} \mathrm{C}$ for $9 \mathrm{~h}$ (inFire HTC, Sirona, Bensheim, Germany), and their fit was checked on the model.

\subsection{Replica Technique}

The internal gap was determined using the replica technique with a fluent polysiloxane impression material (Xantopren Comfort Light, Heraeus, Hanau, Germany). The silicone was mixed with this material, received into the framework crowns and placed on the master model with a pressure of $50 \mathrm{~N}$ using a dynamometer. After $5 \mathrm{~min}$, the framework was carefully removed from the master model. A harder silicone material (Panasil Tray Soft, Kettenbach, Eschenburg, Germany) was mixed evenly and filled into the framework with the fluent silicone. The silicones were both removed from the framework crowns and cut in three planes in the oral-vestibular and mesial-distal directions. The internal gap was measured at 11 locations around the internal surface of each crown (Figure 3).

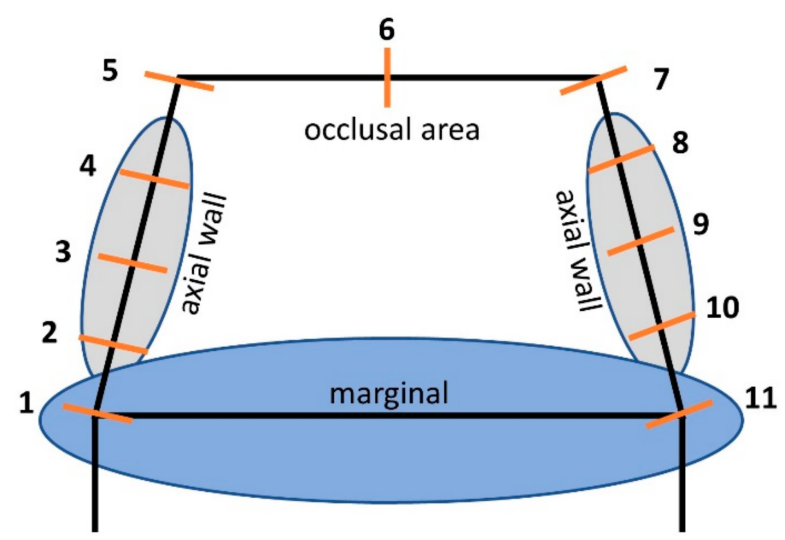

Figure 3. Measurement points at the marginal and internal surfaces of a restoration.

To minimize measurement inaccuracy, each section measurement was repeated five times using a $5 \times$ stereomicroscope (OPMI pico, Zeiss, Jena, Germany). To avoid devicespecific measurement inaccuracies, the microscope unit was calibrated with software using a slide with a calibration circuit of $600 \mu \mathrm{m}$ in diameter every $15 \mathrm{~min}$. The marginal fit was recorded using the technique described by Holmes et al. [29].

\subsection{Statistical Analysis}

Data were imported into Statistical Package for the Social Sciences (SPSS) software (SPSS, Munich, Germany), and mean values were calculated and analyzed as descriptive statistics. One-way analysis of variance was carried out to detect significant differences among the systems in internal and marginal fit at the measurement locations. Bonferroni adjustment was used to control the family-wise error rate. The global level of significance was set at $5 \%$.

\section{Results}

Tables 1-4 show the marginal and internal gaps of the various regions and teeth produced using the four CAD/CAM systems.

Table 1. Performance of the CAD/CAM systems.

\begin{tabular}{ccccc}
\hline System & Mean $(\mu \mathrm{m})$ & SD & Min $(\mu \mathrm{m})$ & Max $(\mu \mathrm{m})$ \\
\hline A & 84 & 43 & 0 & 285 \\
\hline B & 113 & 65 & 0 & 433 \\
\hline C & 132 & 71 & 5 & 579 \\
\hline D & 101 & 67 & 10 & 427 \\
\hline
\end{tabular}


Table 2. Gap sizes of FPDs according to the tooth and the CAD/CAM system $(\mu \mathrm{m})$.

\begin{tabular}{ccccc}
\hline Tooth & (A/B/C/D) & (A/B/C/D) & (A/B/C/D) & (A/B/C/D) \\
\hline & Mean & SD & Min & Max \\
\hline 34 & $83 / 109 / 141 / 110$ & $45 / 66 / 80 / 74$ & $0 / 0 / 5 / 10$ & $285 / 428 / 579 / 416$ \\
\hline 35 & $85 / 125 / 143 / 105$ & $44 / 72 / 69 / 68$ & $0 / 8 / 11 / 10$ & $256 / 433 / 551 / 427$ \\
\hline 37 & $85 / 104 / 113 / 88$ & $41 / 55 / 58 / 55$ & $0 / 0 / 8 / 11$ & $223 / 300 / 505 / 339$ \\
\hline
\end{tabular}

Table 3. Repeated-measures one-way analysis of variance results.

\begin{tabular}{cccc}
\hline Tooth & (A/B/C/D) & (A/B/C/D) & (A/B/C/D) \\
\hline & 34 & 35 & 37 \\
\hline 34 & $-/-/-/-$ & $0.107 /<0.001 / 1.000 /<0.001$ & $0.125 /<0.001 /<0.001 /<0.001$ \\
\hline 35 & & $-/-/-/-$ & $1.000 /<0.001 / 1.000 /<0.001$ \\
\hline 37 & & & $-/-/-/-$ \\
\hline
\end{tabular}

Table 4. Mean gap size with standard deviation, minimum and maximum, according to region ( $\mu \mathrm{m})$.

\begin{tabular}{ccccc}
\hline Region & A & B & C & D \\
\hline Marginal (Q) & $38 / 7 / 24 / 49$ & $72 / 25 / 42 / 125$ & $64 / 19 / 39 / 99$ & $58 / 27 / 32 / 104$ \\
\hline Axial wall (R) & $76 / 24 / 44 / 117$ & $94 / 40 / 53 / 167$ & $141 / 29 / 95 / 226$ & $75 / 25 / 39 / 135$ \\
\hline Occlusal area (S) & $132 / 20 / 89 / 165$ & $178 / 29 / 138 / 250$ & $159 / 27 / 105 / 195$ & $182 / 37 / 134 / 269$ \\
\hline
\end{tabular}

\subsection{Performance of the Systems}

System A showed the smallest mean and maximum gap sizes and the smallest standard deviation, followed by systems D, B and C ( $p<0.001$, Table 1$)$.

\subsection{Gap Size According to Tooth Type}

The gap size of Tooth 37 was significantly smaller than that of Tooth 34 for systems $\mathrm{B}, \mathrm{C}$ and $\mathrm{D}$, and likewise the gap size of Tooth 37 was smaller than that of Tooth 35 for systems B and D. The gap sizes of Teeth 34 and 35 differed significantly between systems $B$ and $\mathrm{D}$ (all $p<0.001$, Tables 2 and 3$)$.

\subsection{Gap Size According to Region}

Systems A, B and C showed a significantly smaller gap size in the marginal area of the framework as compared with the axial and occlusal regions $(p<0.001)$. The occlusal area showed the largest internal gaps with all four systems. The mean gap sizes in the axial wall were between those in the other areas $(p<0.001)$. System A showed the smallest gap sizes in all three regions, with the exception of system $\mathrm{D}(p<0.001$, Table 4$)$.

\section{Discussion}

Marginal adaption is an important means of enhancing tenacity [30-33]. An enlargement of the marginal opening determines the clinical risk of secondary caries and inflammation of the adjacent tissue or the tooth itself. Therefore, it is important that systems produce small and reproducible marginal and internal gaps [31-33]. It can be difficult to standardize parameters, especially those of CAD/CAM systems. These systems typically have varying standards for scanning and grinding. Moreover, the software packages may enable only a few parameters to be changed. Thus, these systems cannot be compared directly in terms of marginal and internal fit. However, a small and reproducible gap size (in terms of internal and marginal fit) is important to avoid periodontal disease and secondary caries. Therefore, the internal and marginal fit was assessed $[18,20,34]$, with the 
hypothesis that there would be no difference in gap sizes milled using the four systems or among the axial, occlusal, and marginal regions of FPDs.

We found significant differences among the systems $(84-101 \mu \mathrm{m})$, as well as among

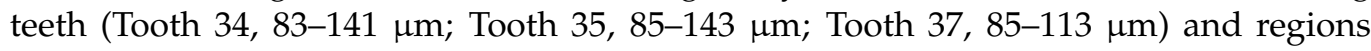
(marginal, 7-49 $\mu \mathrm{m}$; axial, 24-117 $\mu \mathrm{m}$; occlusal, 20-165 $\mu \mathrm{m}$ ), using each system. There are numerous potential reasons for these differences; there are many differences in the construction of the milling apparatus of these CAD/CAM systems as well as the software applications, with different setting options. Therefore, varying numbers of axes and grinding strategies may explain the differences [33-35]. Systems A, B and D are dry-milling units, whereas system $C$ is a wet-milling unit. System A showed the smallest gaps with the smallest standard deviation. Within system A, there was no significant difference among the teeth, indicating consistently small gaps independent of the framework geometry. In contrast, systems B, C and D showed a smaller gap with tooth 37 as compared with teeth 34 and 35, possibly because of the larger radius of tooth 37. This led to higher precision because the grinding wheels of the smallest burs had more space in which to work and the larger die may have been easier to scan. Indeed, differences have been reported in the marginal and internal fit among different dies [34] and molars typically have smaller gaps than premolars [32].

The occlusal area had greater space than the axial wall and the marginal region, as reported by Reich et al., who also confirmed that the marginal gap was smaller than the other areas of the die [22]. Beuer et al. also showed that the occlusal area of zirconia three-unit FDPs had a larger gap than the chamfer area [19]. This may have been due to the grinding strategy, milling process [32,36-38], setting options and/or the manual adjustment process. Greater marginal adaption is intended to achieve marginal sealing after fixation of the FPD using cement or adhesive materials, avoiding secondary caries and periodontal disease. In this respect, a small marginal gap is important for longevity, but an uneven contact situation with punctual contacts instead of a uniform support, especially at the marginal edge, can lead to tensions in the framework and veneering ceramic layer. With respect to the material-related properties of zirconia materials as compared with metal-based restorations, it is also of considerable relevance to achieve a high marginal adaption to take the complete interface with the fixation materials into account. In addition, it is unknown to what extent the size of the marginal gap and the type and quality of fixation material influence restoration longevity. Moreover, it is important to change frequency of cutting burs to achieve small gaps and predictable outcomes for dental CAD/CAM prostheses [39]. Furthermore, whether smaller gaps or the fixation protocol are most important for longevity remains to be determined. Thus, the four CAD/CAM systems were not comparable in terms of the marginal and internal gaps at different locations and according to the tooth. Additionally, different combinations of software and hardware components yielded different results for internal and marginal gaps, as in prior studies $[22,27,37,38]$. It remains to be considered whether, in the future, $3 \mathrm{D}$ printing methods will also generate clinically acceptable prothesis and be relevant in addition to milling [40].

Therefore, the working hypothesis, i.e., that there would be no difference in the internal and marginal gaps of restorations produced using the CAD/CAM systems, was rejected. However, it was not possible to reach conclusions on the clinical impact of the target parameters.

\section{Conclusions}

For FPDs, the four CAD/CAM systems showed significantly different gap sizes between premolars and molars and among the marginal, axial and occlusal regions. Thus, the abutment tooth geometry seems to influence the gap situation. The systems are suitable for clinical applications. The data collected in this study require verification in clinical practice. 
Author Contributions: Conceptualization, K.M.L.; methodology, K.M.L. and M.W.; validation, M.B., P.O.; formal analysis, S.W.; investigation, H.S. (Henning Staedt); resources, K.M.L.; data curation, K.M.L., M.B. and P.W.K.; writing_original draft preparation, K.M.L., S.W. and M.W.; review and editing, H.S. (Henning Staedt), M.W. and P.O.; visualization, P.W.K.; supervision, H.S. (Herbert Scheller).; project administration, K.M.L.; funding acquisition, K.M.L. and H.S. (Herbert Scheller). All authors have read and agreed to the published version of the manuscript.

Funding: This research received no external funding.

Institutional Review Board Statement: Not applicable.

Informed Consent Statement: Not applicable.

Data Availability Statement: Data sharing is not applicable.

Conflicts of Interest: The authors declare no conflict of interest.

\section{References}

1. Manicone, P.F.; Iommetti, P.R.; Raffaelli, L. An overview of zirconia ceramics: Basic properties and clinical applications. J. Dent. 2007, 35, 819-826. [CrossRef]

2. Piconi, C.; Maccauro, G. Zirconia as a ceramic biomaterial. Biomaterials 1999, 20, 1-25. [CrossRef]

3. De Almeida, I.G.; Antunes, D.B.; Braun, N.X.; Restani, A.; Straioto, F.G.; Galhano, G.A. CAD/CAM system influence marginal fit of different ceramic types? Indian J. Dent. Res. 2019, 30, 127-129.

4. Holloway, J.A.; Miller, R.B. The effect of core translucency on the aesthetics of all-ceramic restorations. PPAD 1997, 9, 567-574.

5. Al-Aali, K.A.; Bin-Shuwaish, M.S.; Alhenaki, A.M.; Al Ahdal, K.; Al-Deeb, L.; Maawadh, A.M.; Alhelal, A.; Al-Shehri, H.; Vohra, F.; Abduljabbar, T. Influence of milling systems and marginal configurations on the fit of yttrium stabilized tetragonal zirconia polycrystals (Y-TZP)' copings. J. Appl. Biomater. Funct. Mater. 2020, 18. [CrossRef]

6. Al-Aali, K.A.; Alhamdan, R.S.; Maawadh, A.M.; Vohra, F.; Abduljabbar, T. Influence of contemporary CAD-CAM milling systems on the fit and adaptation of partially stabilized Zirconia fixed partial dentures. Pak. J. Med Sci. 2021, 37, 45-51. [CrossRef]

7. Allahkarami, M.; Hanan, J.C. Mapping the tetragonal to monoclinic phase transformation in zirconia core dental crowns. Dent. Mater. 2011, 27, 1279-1284. [CrossRef] [PubMed]

8. Denry, I.; Kelly, J.R. State of the art of zirconia for dental applications. Dent. Mater. 2008, 24, 299-307. [CrossRef]

9. Mormann, W.H. The evolution of the CEREC system. J. Am. Dent. Assoc. 2006, 137, 7S-13S. [CrossRef]

10. Tanveer, W.; Ridwan-Pramana, A.; Molinero-Mourelle, P.; Koolstra, J.H.; Forouzanfar, T. Systematic Review of Clinical Applications of CAD/CAM Technology for Craniofacial Implants Placement and Manufacturing of Nasal Prostheses. Int. J. Environ. Res. Public Health 2021, 18, 3756. [CrossRef]

11. Lee, S.J.; Jamjoom, F.Z.; Le, T.; Radics, A.; Gallucci, G.O. A clinical study comparing digital scanning and conventional impression making for implant-supported prostheses: A crossover clinical trial. J. Prosthet. Dent. 2021, 15. S0022-3913(21)00028-7.

12. Knechtle, N.; Wiedemeier, D.; Mehl, A.; Ender, A. Accuracy of digital complete-arch, multi-implant scans made in the edentulous jaw with gingival movement simulation: An in vitro study. J. Prosthet. Dent. 2021, 18. S0022-3913(21)00019-6. [CrossRef]

13. Batak, B.; Cakmak, G.; Seidt, J.; Yilmaz, B. Load to failure of high-density polymers for implant-supported fixed, cantilevered prostheses with titanium bases. Int. J. Prosthodont. 2021. [CrossRef]

14. Mormann, W.H.; Curilović, Z. CEREC(R) CAD-CAM ceramic restorations. A case report after 5 years in place. Acta Stomatol. Croat. 1991, 25, 3-10.

15. Bindl, A.; Mörmann, W.H. Marginal and internal fit of all-ceramic CAD/CAM crown-copings on chamfer preparations. J. Oral Rehabil. 2005, 32, 441-447. [CrossRef] [PubMed]

16. Beuer, F.; Neumeier, P.; Naumann, M. Marginal fit of 14-unit zirconia fixed dental prosthesis retainers. J. Oral Rehabil. 2009, 36, 142-149. [CrossRef]

17. Korkut, L.; Cotert, H.S.; Kurtulmus, H. Marginal, Internal Fit and Microleakage of Zirconia Infrastructures: An In-Vitro Study. Oper. Dent. 2011, 36, 72-79. [CrossRef]

18. Abduo, J.; Lyons, K.; Swain, M. Fit of zirconia fixed partial denture: A systematic review. J. Oral Rehabil. 2010, 37, 866-876. [CrossRef] [PubMed]

19. Beuer, F.; Aggstaller, H.; Richter, J.; Edelhoff, D.; Gernet, W. Influence of preparation angle on marginal and internal fit of CAD/CAM-fabricated zirconia crown copings. Quintessence Int. 2009, 40, 243-250.

20. Beuer, F.; Naumann, M.; Gernet, W.; Sorensen, J.A. Precision of fit: Zirconia three-unit fixed dental prostheses. Clin. Oral Investig. 2009, 13, 343-349. [CrossRef] [PubMed]

21. Bindl, A.; Mormann, W.H. Fit of all-ceramic posterior fixed partial denture frameworks in vitro. Int. J. Periodontics Restor. Dent. 2007, 27, 567-575.

22. Reich, S.; Wichmann, M.; Nkenke, E.; Proeschel, P. Clinical fit of all-ceramic three-unit fixed partial dentures, generated with three different CAD/CAM systems. Eur. J. Oral Sci. 2005, 113, 174-179. [CrossRef] [PubMed] 
23. Weaver, J.D.; Johnson, G.H.; Bales, D.J. Marginal adaptation of castable ceramic crowns. J. Prosthet. Dent. 1991, 66, 747-753. [CrossRef]

24. Sulaiman, F.; Chai, J.; Jameson, L.M.; Wozniak, W.T. A comparison of the marginal fit of In-Ceram, IPS Empress, and Procera crowns. Int. J. Prosthodont. 1997, 10, 478-484. [PubMed]

25. Karlsson, S. The fit of Procera titanium crowns: An in vitro and clinical study. Acta Odontol. Scand. 1993, 51, 129-134. [CrossRef] [PubMed]

26. Belser, U.; MacEntee, M.; Richter, W. Fit of three porcelain-fused-to-metal marginal designs in vivo: A scanning electron microscope study. J. Prosthet. Dent. 1985, 53, 24-29. [CrossRef]

27. May, K.B.; Russell, M.M.; Razzoog, M.E.; Lang, B.R. Precision of fit: The Procera AllCeram crown. J. Prosthet. Dent. 1998, 80, 394-404. [CrossRef]

28. Vigolo, P.; Fonzi, F. An In Vitro Evaluation of Fit of Zirconium-Oxide-Based Ceramic Four-Unit Fixed Partial Dentures, Generated with Three Different CAD/CAM Systems, before and after Porcelain Firing Cycles and after Glaze Cycles. J. Prosthodont. 2008, 17, 621-626. [CrossRef]

29. Holmes, J.R.; Bayne, S.C.; Holland, G.A.; Sulik, W.D. Considerations in measurement of marginal fit. J. Prosthet. Dent. 1989, 62, 405-408. [CrossRef]

30. Kokubo, Y.; Tsumita, M.; Kano, T.; Sakurai, S.; Fukushima, S. Clinical marginal and internal gaps of zirconia all-ceramic crowns. J. Prosthodont. Res. 2011, 55, 40-43. [CrossRef] [PubMed]

31. Boening, K.W.; Wolf, B.H.; Schmidt, A.E.; Kästner, K.; Walter, M.H. Clinical fit of Procera AllCeram crowns. J. Prosthet. Dent. 2000, 84, 419-424. [CrossRef]

32. Biscaro, L.; Bonfiglioli, R.; Soattin, M.; Vigolo, P. An In Vivo Evaluation of Fit of Zirconium-Oxide Based Ceramic Single Crowns, Generated with Two CAD/CAM Systems, in Comparison to Metal Ceramic Single Crowns. J. Prosthodont. 2013, $22,36-41$. [CrossRef] [PubMed]

33. Rinke, S.; Fornefett, D.; Gersdorff, N.; Lange, K.; Roediger, M. Multifactorial analysis of the impact of different manufacturing processes on the marginal fit of zirconia copings. Dent. Mater. J. 2012, 31, 601-609. [CrossRef] [PubMed]

34. Beuer, F.; Korczynski, N.; Rezac, A.; Naumann, M.; Gernet, W.; Sorensen, J.A. Marginal and internal fit of zirconia based fixed dental prostheses fabricated with different concepts. Clin. Cosmet. Investig. Dent. 2010, 2, 5-11. [CrossRef] [PubMed]

35. Euán, R.; Figueras-Álvarez, O.; Cabratosa-Termes, J.; Brufau-de Barberà, M.; Gomes-Azevedo, S. Comparison of the Marginal Adaptation of Zirconium Dioxide Crowns in Preparations with Two Different Finish Lines. J. Prosthodont. 2012, $21,291-295$. [CrossRef]

36. Grenade, C.; Mainjot, A.; Vanheusden, A. Fit of single tooth zirconia copings: Comparison between various manufacturing processes. J. Prosthet. Dent. 2011, 105, 249-255. [CrossRef]

37. Oyagüe, R.C.; Sánchez-Jorge, M.I.; Turrión, A.S. Influence of CAD/CAM scanning method and tooth-preparation design on the vertical misfit of zirconia crown copings. Am. J. Dent. 2010, 23, 341-346.

38. Baig, M.R.; Tan, K.B.-C.; Nicholls, J.I. Evaluation of the marginal fit of a zirconia ceramic computer-aided machined (CAM) crown system. J. Prosthet. Dent. 2010, 104, 216-227. [CrossRef]

39. Song, D.-B.; Han, M.-S.; Kim, S.-C.; Ahn, J.; Im, Y.-W.; Lee, H.-H. Influence of Sequential CAD/CAM Milling on the Fitting Accuracy of Titanium Three-Unit Fixed Dental Prostheses. Materials 2021, 14, 1401. [CrossRef] [PubMed]

40. Herpel, C.; Tasaka, A.; Higuchi, S.; Finke, D.; Kühle, R.; Odaka, K.; Rues, S.; Lux, C.J.; Yamashita, S.; Rammelsberg, P.; et al. Accuracy of 3D Printing Compared with Milling-A Multi-Center Analysis of Try-In Dentures. J. Dent. 2021, $24,103681$. [CrossRef] 